\title{
Platelet Function in Patients with Diabetes Mellitus: From a Theoretical to a Practical Perspective
}

\author{
Nicholaos Kakouros, ${ }^{1}$ Jeffrey J. Rade, ${ }^{1}$ Antonios Kourliouros, ${ }^{2}$ and Jon R. Resar ${ }^{1}$ \\ ${ }^{1}$ Johns Hopkins University School of Medicine, and Johns Hopkins Hospital Division of Cardiovascular Disease, Baltimore, \\ MD 21287-073, USA \\ ${ }^{2}$ Imperial College, London SW7 2AZ, UK
}

Correspondence should be addressed to Nicholaos Kakouros, nikos@jhmi.edu

Received 27 April 2011; Accepted 22 June 2011

Academic Editor: A. Marette

Copyright (C) 2011 Nicholaos Kakouros et al. This is an open access article distributed under the Creative Commons Attribution License, which permits unrestricted use, distribution, and reproduction in any medium, provided the original work is properly cited.

Patients with diabetes mellitus have an increased prevalence of vascular disease. Pathologic thrombosis associated with atherosclerotic plaque rupture is a major cause of morbidity and mortality. Platelets are intimately involved in the initiation and propagation of thrombosis. Evidence suggests that platelets from patients with type 2 diabetes have increased reactivity and baseline activation compared to healthy controls. We review the pathophysiology of platelet hyperreactivity in DM patients and its implications in clinical practice, with particular focus on acute coronary syndromes, percutaneous coronary intervention, and novel antiplatelet agents.

\section{Introduction}

Diabetes mellitus, that affects over 25 million people in the US and an estimated 285 million worldwide, is associated with a significant burden of cardiovascular disease $[1,2]$. Patients with type 2 diabetes mellitus (DM2) have a 2- to 4fold increased risk of premature cerebral, coronary, and peripheral vascular disease that together constitute the leading cause of death in these patients $[3,4]$. Unlike the diabetesspecific microvasculopathy, neuropathy, nephropathy, and retinopathy, the macroangiopathic process in patients with diabetes represents an accelerated but pathophysiologically similar process to atherosclerosis in nondiabetic subjects. Thrombotic events of these vascular lesions, particularly in the cerebral and coronary vasculature, can be life threatening.

Normal blood flow and thromboresistance is dependent on vasomotion, blood corpuscular elements, plasma components, and their interaction with the endothelial surface. Rupture of an atherosclerotic plaque exposes subendothelial material that promotes platelet activation and the local initiation of the coagulation cascade that can lead to thrombus formation at the site of endothelial disruption. Acute vascular events, such as myocardial infarction and stroke, are due to such atherothrombotic events rather than gradual progression of luminal stenosis caused by atheromatous plaque.

Patients with DM not only have a greater atheromatous plaque burden but also a thrombotic diathesis that is in part due to changes in the coagulation system with increased levels of plasma fibrinogen, increased intravascular thrombin generation, and reduced fibrinolytic potential $[5,6]$. Equally importantly, however, platelets from patients with diabetes mellitus have dysregulated signaling pathways that lead to an increased tendency to activate and aggregate in response to a given stimulus (platelet hyperreactivity). Platelet activation contributes to the pathology by not only triggering thrombus formation but also causing microcapillary embolization and release of constrictive, oxidative, and mitogenic substances that accelerate progression of local vascular lesions.

Platelet hyperreactivity and increased baseline activation in patients with diabetes is multifactorial and associated with biochemical factors such as hyperglycemia and hyperlipidemia, insulin resistance, and an inflammatory and oxidant state. We aim to review the factors associated with increased platelet reactivity in patients with diabetes mellitus, with a predominant focus on DM type 2. We also discuss the clinical 
relevance of platelet hyperreactivity in diabetic patients with acute coronary instability and the possible choices of antiplatelet agents to suppress platelet activity in this population.

\section{Biochemical Factors Affecting Platelet Function in Diabetes}

Hyperglycemia is the diagnostic hallmark finding in diabetes mellitus and is associated with macrovascular disease even in the prediabetic stage. Hyperglycemia, particularly postprandial, plays a significant role in the DM-associated development of cardiovascular disease as well as the DM prothrombotic state $[7,8]$.

In healthy subjects, without DM, the induction of acute hyperglycemia can lead to increased platelet reactivity and platelet activation as evidenced by increased markers such as soluble P selectin and CD40-ligand [9-11]. Exposure of platelets to hyperosmolar solutions also causes increased reactivity, suggesting that hyperglycemia may have a direct osmotic effect [12]. Both chronic and acute hyperglycemia causes in vivo activation of protein kinase C (PKC), a transduction pathway mediator for many proaggregatory platelet agonists [13]. Platelets from patients with DM, unlike those from healthy individuals, also manifest short-term activation of the calcium-sensitive PKC $\beta$ isoenzyme by acute hyperglycemia even in vitro, in the absence of additional stimuli, indicating an inherent diabetes-related dysregulation of this pathway. A study of patients with type 2 DM undergoing percutaneous coronary intervention (PCI) found that improvements in glycemic control were associated with reduced platelet reactivity [14]. The clinical correlate of these changes is that even mild elevations in preprocedural fasting glucose associate with increased risk of mortality following PCI and, conversely, optimal preprocedural glycemic control (HbAlc $<7 \%)$ in type 2 DM patients is associated with improved clinical outcome $[15,16]$.

Recurrent episodes of hyperglycemia lead to the nonenzymatic interaction between the carbonyl group of the reducing sugar and the primary amino group of a protein leading to a cascade of reactions, the final result of which is a heterogeneous group of compounds known as advanced glycation end products (AGEs) [17]. Some of these AGE cause externalization of platelet membrane phosphatidylserine that leads to surface clotting factor activation and so directly enhance the thrombogenic state [18]. Similarly, the platelets of patients with diabetes have increased glycation levels of surface membrane proteins which cause decreased membrane fluidity and increased platelet sensitivity to agonists. [19, 20].

The final common pathway of platelet activation signaling is platelet aggregation mediated by the glycoprotein $\mathrm{IIb} / \mathrm{III}$ receptor (GPIIb/IIIa) platelet-fibrin interaction. The expression of platelet surface GP IIb/IIIa, as well as of GPIb, which mediates binding to von Willebrand factor, correlates with levels of hemoglobin $\mathrm{A}_{1 \mathrm{C}}$. Hyperglycemia leads to release of larger platelets with more GPIb and GPIIb/IIIa receptors and higher thromboxane forming capacity [21]. Other platelet surface receptors, such as $\mathrm{P}_{2} \mathrm{Y}_{12}$, the target of widely used thienopyridine antiplatelet agents, are also present in increased numbers on DM platelets likely as a result of the altered membrane fluidity dynamics [22]. Activation of the platelet $\mathrm{P}_{2} \mathrm{Y}_{12}$ receptor normally leads to reduced levels of cyclic adenosine monophosphate (cAMP) and subsequently suppressed phosphorylation of vasodilator-stimulated phosphoprotein (VASP-P) by specific protein kinases (PKA) that enhances platelet activation and aggregation (Figure 1) [23]. Platelets from patients with DM have lower levels of cAMP compared with nondiabetics, with consequently upregulated $\mathrm{P}_{2} \mathrm{Y}_{12}$ signaling. Platelets of older diabetics in particular have a higher baseline intracellular calcium level with more enhanced calcium mobilization from intracellular stores in response to thrombin agonism compared to nondiabetic patients $[22,24]$. The higher baseline calcium and lower cAMP make the platelets more reactive such that they activate and aggregate at lower levels of agonist stimulation.

Abnormalities of lipid metabolism, particularly hypertriglyceridemia and low levels of high-density lipoprotein (HDL), are almost invariably found in patients with impaired glucose homeostasis. Hypertriglyceridemia can lead to triglyceride-rich very low density lipoprotein (VLDL) that potentiates platelet activity, an effect mediated partly through apolipoprotein $\mathrm{E}$ and an interaction with the platelet LDL receptor [25]. Interestingly, administration of reconstituted HDL to DM patients can promote cholesterol efflux from platelet membranes which suppresses aggregation [26]. Additionally, the interaction of lipids and glucose with the formation of glycated low-density lipoprotein (LDL) leads to impaired nitric oxide production and increased intraplatelet calcium concentration, further contributing to platelet hyperreactivity [27].

\section{Insulin Effects on Platelets in Diabetes}

Type 2 DM accounts for 90\%-95\% of all DM cases and is characterized by reduced tissue sensitivity to insulin. In the prediabetic stage this insulin resistance is initially met by a compensatory increase in insulin production by pancreatic $\beta$-cells sufficient to maintain fasting euglycemia. In susceptible individuals, the pancreatic $\beta$-cells, under the increased demand, undergo apoptosis leading to a reduction in $\beta$-cell mass. Consequently, the hyperinsulinemia characteristic of the early stages of DM2 progressively gives way to relative and eventually absolute insulin deficiency.

Insulin can directly regulate platelet function via a functional insulin receptor (IR) found on human platelets [28]. The effects of hyperinsulinemia on platelets, however, are complex and disparate between normal individuals and patients with insulin resistance. In vitro experiments using platelets from healthy nonobese individuals reveal that binding of insulin to its receptor causes magnesium to translocate into the platelet and is associated with decreased thrombininduced platelet aggregation and reduced production of proaggregatory thromboxane B2 [29]. Binding of insulin to the IR leads to activation of the insulin receptor substrate 1 (IRS-1) through tyrosine phosphorylation which initiates association with the $\mathrm{G}_{i} \alpha$-subunit. The result is reduced $\mathrm{G}_{i}$ activity that impairs tonic cAMP suppression, and thus leads 


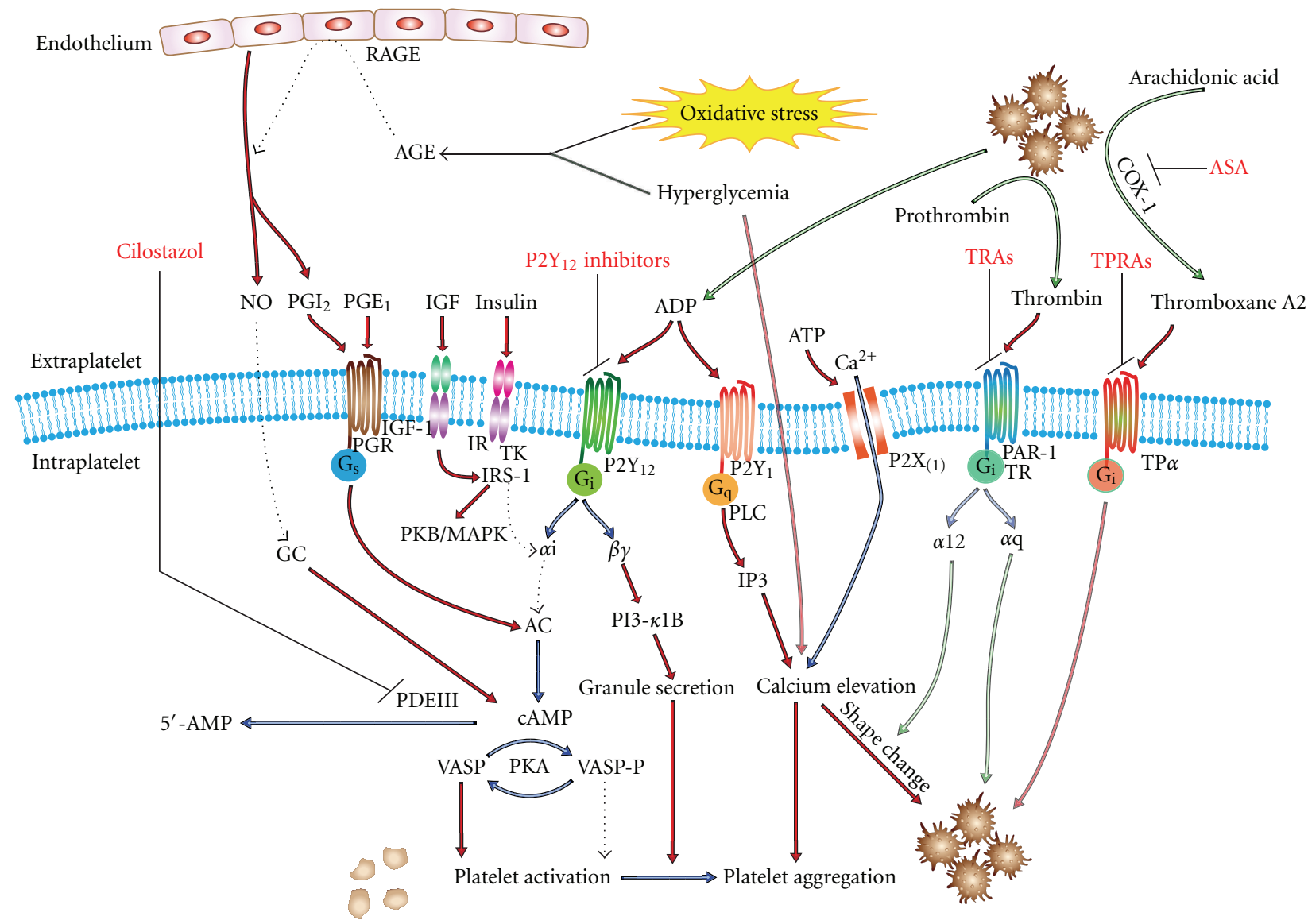

FIGURE 1: Pathways involved in platelet hyperreactivity in DM patients and therapeutic targets. AGE: advanced glycation end products, RAGE: AGE receptors, PKA/B/C: protein kinase A/B/C, MAPK: p38 mitogen-activated protein kinase, TK: tyrosine kinase, NO: nitric oxide, GC: guanylate cyclase, PAR-1 TR: protease activated receptor; thrombin receptor, PI-3: phosphoinositol-3 kinase TRA: thrombin receptor antagonist, TP $\alpha$ : thromboxane receptor, TPRA: thromboxane receptor antagonist, and ASA: acetylsalicylic acid (aspirin). Increased levels of cAMP lead to platelet inhibition through cAMP-dependent protein kinase (PKA) which inhibits signaling though the mitogen-activated protein kinases pathway, receptor activation, thromboxane A2 formation, and activation of key enzymes such as protein kinase C. The prostaglandin, P2Y, P2X, TR, and TP are all seven transmembrane G-protein associated receptors. The TR and TP on the right present novel drug targets; their intracellular effectors are omitted for clarity. Antiplatelet drugs are shown in red.

to increased cAMP intraplatelet levels, blunting of P2Y12 signaling and reduced platelet activity (Figure 1) [30, 31]. It has been suggested that the magnitude of such effects may be limited due to the dimerization of IR subunits with those of the insulin-like growth factor 1 (IGF-1) receptor [32]. Nonetheless, the activation of insulin receptor substrate 1 (IRS-1) and IRS-2, the downstream mediator of the IR, can also occur by binding of IGF-1 to the IGF-1 receptor that is abundantly expressed in platelets leading to increased platelet reactivity [33]. Further, in vivo, experiments in healthy nonobese individuals confirm that insulin inhibits platelet interaction with collagen and attenuates the platelet aggregation effect of agonists [34, 35].

These findings suggest that at least in healthy nonobese individuals, insulin reduces platelet reactivity. Based on this, one may well expect increased platelet reactivity in DM type 1 patients who have absolute insulin deficiency. Similarly, one may postulate that patients with prediabetes or early stages of DM2 who have hyperinsulinemia should have suppressed platelet activity. This is, however, far from being the case. Obesity, a common feature in DM2 patients, can exacerbate or induce insulin resistance yet is associated with platelet hyperreactivity [36]. A euglycemic hyperinsulinemic clamp in obese insulin-resistant patients fails to suppress platelet activity even in the absence of overt DM [36]. Furthermore, obese patients have evidence of increased platelet activation with increased plasma CD40L, increased levels of platelet derived microparticles (released in blood by platelet activation), and higher thromboxane production [37-40]. Insulin sensitization by pioglitazone or weight loss reduces markers of platelet activation in obese women [37, 39].

The mechanism underlying these discrepant effects of insulin on the platelets of healthy individuals versus patients with insulin resistance appears to be impairment of the insulin receptor signaling pathway that occurs not only in tissues but also in platelets [22]. The reduced platelet insulin sensitivity leads to lower cAMP levels, increased intraplatelet calcium concentration, and platelet hyperreactivity $[22,41]$. 
Indeed, insulin therapy in patients with type $2 \mathrm{DM}$ may lead to paradoxical increases in platelet reactivity in vivo [42]. Additionally, platelets from DM patients show IRS-independent impairment of sensitivity to prostacyclin and nitric oxide that normally blunt platelet activation that leads to further increases in platelet reactivity $[43,44]$.

Hyperinsulinemia is, therefore, not protective but potentially detrimental to platelet reactivity in patients with insulin resistance. In addition to its platelet action, insulin has other adverse prothrombotic effects. Induced hyperinsulinemia, particularly in combination with hyperglycemia, leads to a procoagulant state by increasing levels of tissue factor procoagulant activity, decreasing factor VII/VIIa and increasing factor VIII and prothrombin fragment F1.2 [11]. In addition, there is upregulated platelet expression of CD40L and increased monocyte-platelet aggregates, indicative of platelet activation that appears distinct to the pathways of activation by other agonists [45].

\section{Effects of Oxidative Stress and Inflammation on Platelet Function}

Patients with DM have evidence of increased oxidative stress and inflammation compared with healthy subjects. DM is associated with an overproduction of reactive oxygen and nitrogen species and potent radicals, such as hydrogen peroxide and superoxide anion, that can directly lead to platelet activation [46-48]. DM patients have higher levels of 8 -iso-prostaglandin F2 $\alpha$ (8-iso-prostane), a product of nonenzymatic arachidonic acid peroxidation and marker of oxidative stress, particularly in association with acute hyperglycemic episodes [49-51]. Oxidative stress can directly affect platelet reactivity as superoxide anions enhance intraplatelet calcium release upon platelet activation, helping to amplify the platelet aggregation response [52].

The reactive oxygen species enhance the interaction of sugars with proteins during recurrent episodes of hyperglycemia and increase the rate of accumulation of previously mentioned advanced glycation end products (AGEs). These products can interact with AGE receptors (RAGEs) on the endothelium inducing endothelial dysfunction and an inflammatory response (Figure 1) [53]. Normal endothelium produces nitric oxide $(\mathrm{NO})$ and prostacyclin which inhibit platelet activation under physiological conditions. Endothelial dysfunction leads to reduced production on $\mathrm{NO}$ and prostacyclin and so contributes to platelet hyperreactivity $[54,55]$. NO can be oxidized by superoxide anions, leading to further reductions in its half-life and antiplatelet action [52].

Inflammation, associated with endothelial dysfunction, modulates the levels of proteins involved in platelet activation, such as increasing levels of the Fc $\gamma$-RIIA receptor that mediates enhanced activation in response to collagen [56]. Both oxidative stress and inflammation are also associated with accelerated turnover of platelets in patients with DM compared with healthy individuals, as indicated by the finding of immature, reticulated circulating platelets [57]. As platelet size correlates with activity, these large platelets are inherently hyperreactive and less responsive to antiplatelet therapy with aspirin and clopidogrel $[58,59]$.

\section{Clinical Implications of Platelet Hyper-Reactivity in Diabetes}

Low-dose aspirin remains the cornerstone of antiplatelet therapy by reducing the risk of MI, stroke, or cardiovascular death in intermediate-to-high-risk patients with established vascular disease by $20 \%$ [60]. Nonetheless, some patients' platelets remain reactive despite aspirin therapy when assessed by in vitro laboratory tests using a variety of platelet agonists. Multiple studies have found these patients to be at higher risk of atherothrombotic events [61-65]. The problem is particularly prominent in DM patients, $10 \%-40 \%$ of whom display high residual platelet reactivity on biochemical testing despite aspirin therapy $[66,67]$. Although often termed "aspirin resistance", this is, in most cases, a misnomer as failure of aspirin to achieve its expected pharmacological effect of inhibiting the conversion of arachidonic acid to TXA2 by the platelet cyclooxygenase- 1 (COX-1) enzyme is actually quite rare with a prevalence of less than $5 \%$ in multiple studies $[68,69]$.

A more appropriate and descriptive term for persistent agonist-induced platelet activation despite aspirin therapy is "high on-treatment platelet reactivity" (HTPR). Activated platelets produce the eicosanoid thromboxane A2 (TXA2), which creates a local positive-feedback loop that amplifies the activation response of the platelets to most agonists as well as activating bystander quiescent platelets. Aspirin irreversibly inhibits COX-1, the key enzyme in the conversion of arachidonic acid into TXA2 and thus interferes with the thromboxane feedback loop (Figure 1). Aspirin, therefore, limits the platelet response to weak agonists such as ADP and collagen though potent platelet agonists, such as thrombin, can still elicit strong platelet activation [70].

Due to the multiple pathophysiological mechanisms discussed above, patients with DM have hyperreactive platelets that are more sensitive to activation even by relatively weak agonists. As a result, even though aspirin may effectively block the TXA2 positive feedback loop, platelets of affected patients continue to manifest HTPR that places them at elevated risk of future thrombotic events. The inability of aspirin monotherapy to sufficiently blunt platelet reactivity provides the rationale for dual antiplatelet therapy in certain patients at high-risk of thrombotic events, such as patients with acute coronary syndrome (ACS) or undergoing PCI [71] and drives the search for more potent and specific antiplatelet agents with a more consistent platelet suppressing effect.

\subsection{Thienopyridines-Clopidogrel. Similar to TXA2, ADP al-} so exerts a positive feedback on platelet reactivity. Platelet activation leads to the release of adenosine diphosphate (ADP) from the dense granules that binds to platelet $\mathrm{P}_{2} \mathrm{Y}_{1}$ and $\mathrm{P} 2 \mathrm{Y}_{12}$ receptors, potentiating platelet activation. The thienopyridines were the first class of alternative antiplatelet agents that became available and irreversibly inhibit the $\mathrm{P}_{2} \mathrm{Y}_{12}$ (but not the $\mathrm{P}_{2} \mathrm{Y}_{1}$ ) ADP platelet receptor, thus preventing the positive feedback amplification of agonist-induced platelet activation. The first thienopyridine compound, ticlopidine, was associated with noninsignificant rates of hematologic 
side effects, such as neutropenia and thrombotic thrombocytopenic purpura, and was superseded by the better tolerated second-generation agent, clopidogrel.

Patients with a high-risk of thrombotic complications, such as post-ACS or undergoing PCI, have been shown to benefit from aggressive dual antiplatelet therapy (DAT) consisting of aspirin in conjunction with clopidogrel. In the landmark Clopidogrel in Unstable Angina to Prevent Recurrent Events (CURE) study of ACS patients, patients with DM had a higher absolute risk reduction of primary outcome ( $16.7 \%$ to $14.2 \%$ ) than non-DM patients (9.9\% to $7.9 \%$ ), albeit with a lower relative risk reduction from clopidogrel therapy compared to the overall cohort (15\% versus $20 \%$, resp.) $[71,72]$.

Clopidogrel does, however, have a number of drawbacks. It has a relatively slow onset of antiplatelet action and large inter-patient variability of platelet response due to variations in drug metabolism. Both ticlopidine and clopidogrel are prodrugs that require metabolic activation via a two-step process involving cytochrome P450 (CYP) isoenzymes. Polymorphisms in genes encoding for several of the CYP enzymes cause ineffective or even absent metabolic activation of clopidogrel in some patients resulting in HTPR. Patients with HTPR, despite treatment with aspirin and clopidogrel are known to be at increased risk of thromboembolic complications after drug eluting stent implantation [73-76]. Posttreatment platelet reactivity assessment with the VerifyNow $\mathrm{P} \mathrm{Y}_{12}$ system (Accumetrix, Inc., San Diego, Calif, USA) gives particularly good predictability of such thrombotic events [77].

DM has been found to be a predictor of HTPR despite clopidogrel therapy in a number of studies and populations $[6,78,79]$. In the Optimizing Antiplatelet Therapy in Diabetes Mellitus (OPTIMUS) trial, two thirds of diabetic patients were considered to have suboptimal response to aspirin and clopidogrel DAT, defined as a $>50 \%$ residual platelet aggregation following ADP agonist stimulation. These poor responders had significant platelet reactivity suppression only with $150 \mathrm{mg}$ daily doses of clopidogrel but not the usual $75 \mathrm{mg}$ daily dose [80]. In a recent study, HTPR, despite clopidogrel therapy in patients with DM, was associated with a fourfold increase in periprocedural myocardial infarction compared to DM patients with suppressed platelet reactivity [81]. Interestingly, higher doses of clopidogrel (such as $600 \mathrm{mg}$ loading dose) may overcome HTPR in some patients despite suboptimal glycemic control [82].

The HTPR problem may be further compounded by DM therapy. A recent study found that DM patients on sulfonylureas had a more than 2-fold higher rate of HTPR on clopidogrel, possibly due to competition of the two drugs for metabolism by the CYP2C9 cytochrome isoenzyme leading to reduced biotransformation of clopidogrel to its active metabolite [83].

It is thought that the principal underlying pathophysiological abnormality responsible for the increased rates of clopidogrel HTPR in DM is that platelets from patients with DM have lower levels of cAMP compared with nondiabetics. Lower baseline cAMP leads to upregulated $\mathrm{P}_{2} \mathrm{Y}_{12}$ signaling and, consequently, a lower degree of platelet inhibition by
P2 $\mathrm{Y}_{12}$ antagonists. Increasing baseline platelet cAMP levels would, therefore, seem a reasonable approach in reversing this inherent resistance of DM platelets to $\mathrm{P}_{2} \mathrm{Y}_{12}$ inhibition.

5.2. Use of Cilostazol to Overcome Clopidogrel Platelet Resistance in Diabetes. Cilostazol is a phosphodiesterase-3 inhibitor that increases intraplatelet cAMP levels and could therefore be theorized to help overcome platelet resistance to $\mathrm{P} \mathrm{Y}_{12}$ inhibition [84]. As expected, in the ACCEL-RESISTANCE study, cilostazol reduced platelet activity more effectively than doubling the standard dose of clopidogrel to $150 \mathrm{mg}$ in patients with high platelet activity following clopidogrel loading [85]. Increased inhibition of platelet P2 $\mathrm{Y}_{12}$ signaling by the addition of $100 \mathrm{mg}$ cilostazol to DAT in type 2 DM patients following PCI was also demonstrated in the randomized double-blind placebo controlled OPTIMUS-2 study [86]. This increased platelet inhibition translated into a favorable clinical outcome in the DECREASE registry of almost 3,100 patients treated with aspirin/clopidogrel DAT or DAT plus cilostazol following PCI with a drug-eluting stent [87]. Triple antiplatelet therapy (TAT) with cilostazol significantly reduced 12 -month risks of stent thrombosis and MI compared with DAT without increased risk of bleeding complications.

Interestingly, the recent CILON-T trial recruited 960 patients with ACS receiving DES and randomized them in an open-label fashion to DAT (aspirin and clopidogrel) or TAT (aspirin, clopidogrel, and cilostazol) [88]. Approximately one third of these patients had DM and half presented with ACS. The addition of cilostazol enhanced DAT platelet inhibition but there was no difference in composite adverse events at 6 months in the entire cohort or in the subgroup of DM patients. The authors hypothesized that the positive chronotropic effect of cilostazol may have had deleterious effects in the acute post-ACS setting that masked any favorable antiplatelet action. Interestingly, a genomics subgroup analysis of CILON-T revealed that patients with specific cytochrome $\mathrm{P} 450$ polymorphisms leading to impaired clopidogrel activation had higher rates of HTPR if they were randomized to DAT, but not if they received TAT [89]. This important finding suggests that HTPR may arise from the dysregulation of platelet activation mechanisms, as found in patients with $\mathrm{DM}$, independently of the patient's ability to activate clopidogrel. It is also noteworthy that female patients (at lower risk of events), and elderly patients (at higher risk of bleeding complications) had more favorable outcomes with DAT rather than with triple therapy including cilostazol.

Although cilostazol may have some beneficial effect in DM patients by improving platelet response to DAT, there are concerns regarding its use in ACS. It is, furthermore, contraindicated in patients with congestive heart failure, further limiting its utility in this acute setting.

5.3. Newer Antiplatelet Agents in DM Patients Undergoing PCI. Diabetic patients with ACS have been shown to benefit from an early invasive strategy by PCI and derive a greater benefit from powerful platelet inhibition with glycoprotein IIb/IIIa receptor antagonists (GPRAs) than patients without DM [90]. In real-world clinical practice, however, patients 
with DM are offered invasive therapy and GPRAs even less frequently than nondiabetics [91]. The reason for this discrepancy is unclear but may be due to the higher incidence of moderate-to-severe renal impairment in DM patients [92]. Furthermore, the role of GPRAs in the management of these patients may need to be revised in view of the emergence of newer, faster acting and potent antiplatelet agents.

Prasugrel. Prasugrel is a third-generation thienopyridine antiplatelet agent that has received approval by the US Food and Drug Administration (FDA) and the European Medicines Agency (EMEA). Like clopidogrel and ticlopidine, prasugrel is a pro-drug that requires metabolic activation. Unlike these other agents, however, prasugrel is activated by a one-step hepatic reaction that is unaffected by CYP polymorphisms $[93,94]$. This leads to more rapid and consistent antiplatelet effects compared to either ticlopidine or clopidogrel. The Trial to Assess Improvement in Therapeutic Outcomes by Optimizing Platelet Inhibition With PrasugrelThrombolysis in Myocardial Infarction 38 (TRITON-TIMI 38) enrolled 13,608 patients with intermediate-to-high-risk ACS or ST elevation MI undergoing PCI who were randomized to clopidogrel versus prasugrel. A subgroup analysis of patients with DM from this study showed that these patients benefited from a higher reduction in the primary end point (a composite of cardiovascular death, myocardial infarction, and stroke) than subjects without DM (hazard ratio- $-\mathrm{HR}$ 0.72 versus $0.86, P<0.001)$, particularly if on insulin therapy (HR 0.63, $P=0.009$ ). The DM patients also had no significant increase in hemorrhagic complications unlike the non-DM subjects [95]. Consequently, the net clinical benefit from prasugrel was greater for DM patients than for those without DM. Based on these findings, prasugrel was officially endorsed by the UK National Institute for Health and Clinical Excellence (NICE) in October 2009 for limited use in combination with aspirin in high-risk ACS patients undergoing PCI (http://www.nice.org.uk/TA182). Along with patients undergoing primary PCI for ST elevation MI (STEMI) and patients with prior stent thrombosis whilst on clopidogrel therapy, patients with DM were singled out as a patient group most likely to benefit from this enhanced antiplatelet therapy. In the USA, the joint ACC/AHA/SCAI guidelines endorse the use of prasugrel for patients with STEMI undergoing PCI unless this is contraindicated due to a prior history of stroke or transient ischemic attack [96].

Nonthienopyridine P2 $\mathrm{Y}_{12}$ Receptor Antagonis. Nonthienopyridine $\mathrm{P}_{2} \mathrm{Y}_{12}$ Receptor Antagonis including ticagrelor, cangrelor and elinogrel, that do not require metabolic activation are also being investigated. The phase 3 CHAMPION trials of the short-acting intravenous reversible $\mathrm{P}_{2} \mathrm{Y}_{12}$ inhibitor cangrelor were terminated due to poor interim results, while a phase 3 trial of elinogrel, unique in having both an oral and intravenous preparation, is in the planning stage [97, 98]. Ticagrelor, a member of a new cyclopentyl triazolo pyrimidine class of antiplatelet drugs has been more extensively investigated. It is an orally active adenosine triphosphate (ATP) derivative that reversibly inhibits the $\mathrm{P} 2 \mathrm{Y}_{12} \mathrm{ADP}$ receptor. It provides more consistent platelet inhibition than clopidogrel, as it does not require metabolic activation that may be affected by genetic polymorphisms, and its metabolite is also an active $\mathrm{P}_{2} \mathrm{Y}_{12}$ inhibitor [99]. It is also a more potent agent, leading to $30 \%$ more platelet inhibition than clopidogrel [100] and has a more rapid onset and offset of antiplatelet effect [101]. The phase 3 PLATO (PLATelet inhibition and patient Outcomes) trial randomized more than 18,500 patients with STEMI or NSTEMI between clopidogrel and ticagrelor [102]. Overall, ticagrelor was associated with a lower composite endpoint of cardiovascular death, MI, or stroke with no increase in major bleeding. A subgroup analysis of PLATO data showed that DM patients with ACS, representing approximately $25 \%$ of the cohort, also benefited from a greater primary endpoint reduction with ticagrelor than clopidogrel irrespective of glycemic control. Additionally, these patients enjoyed a reduction of coronary artery bypass related bleeding, the latter being likely due to the reversible nature of $\mathrm{P}_{2} \mathrm{Y}_{12}$ inhibition by ticagrelor [103]. Side effects of note were asymptomatic ventricular pauses and dyspnea that proved clinically limiting and led to drug discontinuation in $1 \%$ of patients. Nonetheless, underweight patients (below their respective gender median), patients not on lipid-lowering drugs at randomization, and North American patients had notably lower or no benefit from ticagrelor treatment. The latter finding, postulated to be related to the higher dose of aspirin used in North American patients, led the US Food and Drug Administration (FDA) to decline initial approval of the drug pending further review of the data, expected later this year.

Notably, in both the TRITON-TIMI 38 and the PLATO trials, the newer agents were predominantly compared to "standard" clopidogrel dosing consisting of a $300 \mathrm{mg}$ load followed by $75 \mathrm{mg}$ daily maintenance. In the more recent OASIS-7 (CURRENT) trial of ACS patients undergoing PCI, a "high-dose" clopidogrel regimen (600 mg loading and $150 \mathrm{mg}$ daily for the first week after PCI) reduced thrombotic endpoints compared to the "standard" dosing and marginally improved a composite primary outcome of cardiovascular death, myocardial infarction, or stroke at 30 days post-PCI. Although this result is an analysis of the PCI subgroup it is consistent with a meta-analysis of previous studies [104]. None of the TRITON-TIMI 38 and fewer than $20 \%$ of patients in the PLATO trial received $600 \mathrm{mg}$ clopidogrel; consequently, the relative benefit of prasugrel or ticagrelor compared to high-dose clopidogrel remains uncertain. Nonetheless, in the GRAVITAS study 5,400 patients undergoing, predominantly elective, PCI had platelet function testing using the Verify Now assay (Accumetrics, Inc., San Diego, Calif, USA). Those found to have HTPR despite DAT, a finding significantly more prominent in the DM subgroup, were randomized to standard DAT or high-dose clopidogrel loading and double-dose clopidogrel daily for 6 months. Although patients who were treated with higher doses of clopidogrel tended to have lower $\mathrm{P}_{2} \mathrm{Y}_{12}$ platelet reactivity there was no difference in the primary endpoint of cardiovascular death, myocardial infarction, and stent thrombosis [105]. A proposed mechanism for this failure is that highdose clopidogrel is insufficient to overcome platelet hyperreactivity in these patients who may fare better with more 
TABLE 1: A summary of key antiplatelet drug clinical trials in patients with diabetes mellitus.

\begin{tabular}{llll}
\hline Study $N(\mathrm{DM} /$ total $)$ Setting & Groups & $\begin{array}{l}\text { Endpoint } \\
\text { Follow-up period }\end{array}$ & Pertinent findings \\
\hline \multicolumn{3}{c}{ Clopidogrel } \\
\hline
\end{tabular}

CURE

Clopidogrel in unstable Angina to prevent recurrent events
Clopidogrel (300 mg LD, $75 \mathrm{mg} \mathrm{MD)}$ versus

2,838/12,562 UA, NSTEMI placebo in addition to standard aspirin therapy. RCT
Higher absolute risk reduction of primary outcome (16.7\% to $14.2 \%$ ) in DM than non-DM patients (9.9\% to $7.9 \%)$, but a clopidogrel benefit of borderline statistical significance with lower relative risk reduction compared to the overall cohort ( $15 \%$ versus $20 \%$ resp.)

Two thirds (40/64) of screened DM patients had "suboptimal response to clopidogrel” $75 \mathrm{mg}$

OPTIMUS

Optimizing antiplatelet therapy in Diabetes Mellitus

$40 / 40$

DM patients on DAT with HTPR
Clopidogrel 75 mg MD

versus Clopidogrel $150 \mathrm{mg}$ MD. RCT
Platelet function testing at 60 days
(HTPR).

atelet aggregation in response to ADP was significantly reduced in DM patients receiving clopidogrel $150 \mathrm{mg}$ compared with the $75 \mathrm{mg}$ group

$(P=0.002)$
OASIS-7 (CURRENT) usage to reduce recurrent planned for invasive strategy

\begin{tabular}{|c|c|c|c|}
\hline $\begin{array}{l}\text { OASIS-7 (CURRENT) } \\
\text { Clopidogrel and } \\
\text { Aspirin optimal dose } \\
\text { usage to reduce } \\
\text { recurrent } \\
\text { events-seventh } \\
\text { organization to assess } \\
\text { strategies in ischemic } \\
\text { syndromes }\end{array}$ & $5,880 / 25,087$ & $\begin{array}{l}\text { ACS patients } \\
\text { planned for } \\
\text { invasive } \\
\text { strategy }\end{array}$ & $\begin{array}{l}\text { Clopidogrel ( } 600 \mathrm{mg} \mathrm{LD} \text {, } \\
150 \mathrm{mg} \text { MD for } 6 \text { days, } \\
\text { then } 75 \mathrm{mg} \mathrm{MD}) \text { versus } \\
\text { Clopidogrel ( } 300 \mathrm{mg} \mathrm{LD} \text {, } \\
75 \mathrm{mg} \mathrm{MD}) \text {. } \\
\text { Aspirin ( } 300-325 \mathrm{mg} \\
\text { MD) versus aspirin } \\
(75-100 \mathrm{mg} \mathrm{MD}) \text {. } \\
2 \times 2 \text { factorial design }\end{array}$ \\
\hline
\end{tabular}

No overall statistical significance between the two clopidogrel regimes on primary endpoint. No significant difference between higher-dose and lower-dose aspirin with respect to the primary outcome. Reduced secondary outcome of stent thrombosis with high-dose Clopidogrel in subset of patients undergoing PCI

cardiovascular death, MI, or stroke. 30 days

$41 \%$ of screened patients (2214

\begin{tabular}{|c|c|c|c|c|}
\hline $\begin{array}{l}\text { GRAVITAS } \\
\text { Gauging } \\
\text { responsiveness with a } \\
\text { verifynow } \\
\text { assay-impact on } \\
\text { Thrombosis and } \\
\text { safety }\end{array}$ & $1,004 / 2,214$ & $\begin{array}{l}\text { Patients post } \\
\text { PCI with } \\
\text { HTPR on } \\
\text { DAT by } \\
\text { verifynow } \\
\text { assay }\end{array}$ & $\begin{array}{l}\text { Clopidogrel ( } 75 \text { mg MD) } \\
\text { versus Clopidogrel } \\
\text { (repeat } 600 \mathrm{mg} \text { LD, } \\
150 \mathrm{mg} \mathrm{MD})\end{array}$ & $\begin{array}{l}\text { Composite } \\
\text { cardiovascular death, } \\
\text { MI, stent thrombosis. } \\
\text { Bleeding safety } \\
\text { endpoint. } \\
6 \text { months }\end{array}$ \\
\hline
\end{tabular}

$41 \%$ of screened patients ( 2214 of 5429) had HTPR on Clopidogrel $75 \mathrm{mg}$. Lower P2 $\mathrm{Y}_{12}$ platelet reactivity with higher-dose Clopidogrel but no difference in the primary composite endpoint at 6 months

\section{CHARISMA}

Clopidogrel for High Atherothrombotic risk and ischemic stabilization, management, and avoidance
Patients with stable cardio- Clopidogrel $75 \mathrm{mg}$ $6,556 / 15,603$ vascular disease or multiple risk 75-162 mg daily factors

\section{Composite} cardiovascular death, MI, stroke. Median 28 months follow-up
No difference in primary endpoint between aspirin and DAT.

Increased hemorrhagic events with DAT.

Increased mortality in patients with DM nephropathy treated with DAT

\section{Cilostazol}

ACCEL/RESISTANCE

Adjunctive Cilostazol

versus high

maintenance dose

Clopidogrel in

patients with

Clopidogrel resistance
Patients with Clopidogrel $75 \mathrm{mg}+$ HTPR after cilostazol $100 \mathrm{mg}$ bd clopidogrel versus Clopidogrel $300 \mathrm{mg} \quad 150 \mathrm{mg}$. All patients on loading aspirin $200 \mathrm{mg}$ /day. RCT
Adjunctive cilostazol reduced the

Platelet function testing at 30 days rate of HTPR and intensified platelet inhibition as compared with high-maintenance dose clopidogrel $150 \mathrm{mg} /$ day 
TABle 1: Continued.

\begin{tabular}{|c|c|c|c|c|c|}
\hline Study & $N(\mathrm{DM} /$ total $)$ & Setting & Groups & $\begin{array}{l}\text { Endpoint. } \\
\text { Follow-up period }\end{array}$ & Pertinent findings \\
\hline $\begin{array}{l}\text { OPTIMUS-2 } \\
\text { Optimizing } \\
\text { antiplatelet therapy } \\
\text { in diabetes mellitus } 2\end{array}$ & $20 / 20$ & $\begin{array}{l}\text { DM patients } \\
\text { on DAT } \\
\text { (aspirin } \\
81 \mathrm{mg} \text {, } \\
\text { clopidogrel } \\
75 \text { mg daily) }\end{array}$ & $\begin{array}{l}\text { Adjunctive Cilostazol } \\
100 \mathrm{mg} \text { bd versus } \\
\text { placebo. } \\
\text { 2-week cross-over } \\
\text { double-blind RCT } \\
\text { design }\end{array}$ & Platelet function & $\begin{array}{l}\text { Enhanced } \mathrm{P}_{2} \mathrm{Y}_{12} \text { platelet receptor } \\
\text { signaling inhibition with } \\
\text { cilostazol in adjunct to standard } \\
\text { DAT. } \\
\text { Significant side effects with } \\
\text { cilostazol with high rate of drug } \\
\text { withdrawal }\end{array}$ \\
\hline $\begin{array}{l}\text { DECREASE Registry } \\
\text { drug-eluting stenting } \\
\text { followed by } \\
\text { Cilostazol treatment } \\
\text { reduces adverse } \\
\text { serious cardiac events }\end{array}$ & $867 / 3,099$ & $\begin{array}{l}\text { Patients after } \\
\text { DES } \\
\text { implantation }\end{array}$ & $\begin{array}{l}\text { DAT (aspirin,and } \\
\text { clopidogrel) versus TAT } \\
\text { (aspirin, clopidogrel and } \\
\text { cilostazol). } \\
\text { Registry }\end{array}$ & $\begin{array}{l}\text { Death, MI and stent } \\
\text { thrombosis. } \\
12 \text { months }\end{array}$ & $\begin{array}{l}\text { Cilostazol significantly reduced } \\
\text { the } 12 \text {-month risk of stent } \\
\text { thrombosis and MI after DES } \\
\text { implantation when added to } \\
\text { DAT. } \\
\text { No increase in major or minor } \\
\text { bleeding complications }\end{array}$ \\
\hline $\begin{array}{l}\text { CILON-T } \\
\text { Influence of } \\
\text { CILostazol-based } \\
\text { triple antiplatelet } \\
\text { therapy ON ischemic } \\
\text { complication after } \\
\text { drug-eluting stent } \\
\text { implantation }\end{array}$ & $307 / 960$ & $\begin{array}{l}\text { Patients after } \\
\text { DES } \\
\text { implantation }\end{array}$ & $\begin{array}{l}\text { DAT (aspirin and } \\
\text { clopidogrel) versus TAT } \\
\text { (aspirin, clopidogrel and } \\
\text { cilostazol). } \\
\text { Open-label, blind } \\
\text { evaluation }\end{array}$ & $\begin{array}{l}\text { Cardiac death, MI, } \\
\text { ischemic stroke, and } \\
\text { TLR at } 6 \text { months }\end{array}$ & $\begin{array}{l}\text { Enhanced platelet inhibition } \\
\text { with TAT but no difference in } \\
\text { composite adverse events at } 6 \\
\text { months (entire cohort or DM } \\
\text { patients). } \\
\text { Higher adverse events with TAT } \\
\text { versus DAT in females and } \\
\text { elderly patients }\end{array}$ \\
\hline
\end{tabular}

\section{TRITON-TIMI 38}

Trial to assess improvement in therapeutic outcomes by optimizing platelet inhibition With PrasugrelThrombolysis in Myocardial infarction 38
Patients with

moderate-to- Clopidogrel (300 mg LD high-risk and $75 \mathrm{mg} \mathrm{MD}$ ) versus

$3,146 / 3,608$ UA/NSTEMI, Prasugrel (60 mg LD and STEMI for $10 \mathrm{mg} \mathrm{MD}$ ) PCI
DM patients on prasugrel had higher reduction in endpoint compared to clopidogrel than non-DM patients (HR 0.72 versus $0.86, P<0.001)$. Benefit of prasugrel was greater amongst DM patients on insulin (HR, 0.63; $P=0.009$ ).

Patients without DM had significantly increased risk of stroke. Bleeding safety endpoint TIMI major hemorrhage on prasugrel versus clopidogrel (1.6\% versus $2.4 \% ; P=0.02$ ) but DM patients had similar bleeding rates on the two drugs $(P=0.81)$.

Greater net treatment benefit with prasugrel versus clopidogrel in DM patients

\begin{tabular}{|c|c|c|c|c|}
\hline $\begin{array}{l}\text { PLATO } \\
\text { platelet inhibition } \\
\text { and patient outcomes }\end{array}$ & $4,662 / 18,624$ & $\begin{array}{l}\text { moderate-to- } \\
\text { high-risk } \\
\text { UA/NSTEMI, } \\
\text { STEMI for } \\
\text { PCI }\end{array}$ & $\begin{array}{l}\text { Clopidogrel ( } 300 \mathrm{mg} \mathrm{LD} \\
\text { and } 75 \mathrm{mg} \mathrm{MD}) \text { versus } \\
\text { Ticagrelor ( } 180 \mathrm{mg} \mathrm{LD} \\
\text { and } 90 \mathrm{mg} \text { bd MD) }\end{array}$ & $\begin{array}{l}\text { CV death, MI and } \\
\text { stroke. } \\
\text { Bleeding safety } \\
\text { endpoint. } \\
\text { 6-12months }\end{array}$ \\
\hline
\end{tabular}

Ticagrelor was associated with a lower composite endpoint with no increase in bleeding in the entire cohort as well as DM patients.

Effects were irrespective of DM status, insulin treatment, and glycemic control

ACS: acute coronary syndrome, ADP: adenosine diphosphate, bd: twice daily, DAT: dual antiplatelet therapy, DES: drug-eluting stent, DM: diabetes mellitus, HR: hazard ratio, HTPR: high on-treatment platelet reactivity, LD: loading dose, MD: maintenance dose, MI: myocardial infarction, NSTEMI: non-ST elevation MI, RCT: randomized control trial, STEMI: ST-elevation MI, TAT: triple antiplatelet therapy, UA: unstable angina. 
potent therapy such as with prasugrel, ticagrelor, or other novel agents.

As many of the deranged intracellular pathways in DM contribute to $\mathrm{P}_{2} \mathrm{Y}_{12}$ inhibition, it is hoped that agents that can inhibit alternative activation pathways may be helpful in DM patients. One such potential novel target is the proteaseactivated receptor 1 that mediates the effect of thrombin, the most potent physiologic platelet activator. Thrombin receptor antagonism has the additional theoretical benefit of blocking the cellular effects of thrombin without inhibiting the thrombin-mediated cleavage of fibrinogen (that is the final stent of the coagulation cascade) and may, therefore, cause less bleeding than other antithrombotic agents [106109]. At least one such agent is currently being trialed in DM patients (clinicaltrials.gov: NCT00855374). Similarly, the thromboxane receptor provides a possible therapeutic target in blocking the TXA2 feedback loop. A TP selective antagonist is currently in phase III clinical trial for prevention of recurrent ischemic complications in patients with prior transient ischemic cerebral events [110].

5.4. Antiplatelet Therapy in DM Patients with Stable Vasculopathy. It must, finally, be noted that although DM patients have higher baseline platelet reactivity, this does not appear sufficient to warrant aggressive antiplatelet therapy in the chronically stable DM patient. DM patients with asymptomatic, stable coronary, cerebrovascular, or peripheral vascular disease did not have a reduction of MI, stroke or cardiovascular death with dual antiplatelet therapy (DAT) of aspirin and clopidogrel compared to aspirin alone in the CHARISMA trial [72]. DAT was, however, associated with increased hemorrhagic events. Interestingly, a posthoc analysis of this large trial suggested that, in the presence of diabetic nephropathy, the addition of clopidogrel to the antiplatelet regime of such patients was, in fact, associated with an increase in overall cardiovascular mortality, though the pathophysiological mechanism of this finding is unclear $[111,112]$. Similarly, meta-analyses of the use of aspirin for the primary prevention of cardiovascular events suggest a modest reduction in cardiovascular events (MI and stroke) [113]. The data remain inconclusive to recommend aspirin use for primary prevention in all DM patients, though it should be prescribed to DM patients at $>10 \% 10$-year risk of cardiovascular disease and considered in patients at intermediate $(5 \%-10 \%)$ risk according to the recent position statement of the American Diabetes Association [114] (Table 1).

\section{Conclusion}

Patients with DM have evidence of platelet hyperreactivity and increased baseline platelet activation. This results from a combination of factors including the effects of insulin, hyperglycemia, hyperlipidemia, endothelial dysfunction, oxidative stress, and inflammatory state. As our understanding of the molecular and genetic bases underpinning pathophysiologi$\mathrm{cal}$ and therapeutic interactions expands, we can move closer towards individualized patient treatment.
Antiplatelet drugs interfere with platelet activation in the setting of pathologic atherothrombosis, but potentially also during physiologic hemostasis. There is currently no "magic bullet" antiplatelet agent that can effectively abolish atherothrombosis with no hemorrhagic penalty. The group of thrombin receptor antagonists is promising in this respect as this pathway may be of most significance in pathologic atherothrombosis rather than physiologic hemostasis. Currently bleeding is, therefore, a major factor to determine the risk-to-benefit utility of present and upcoming antiplatelet drugs. In view of the enhanced platelet functionality in DM patients, this ratio and, consequently, the choice of antiplatelet agents may differ from the general population.

Patients with DM represent an important subgroup who may enjoy a greater net clinical benefit from a more potent antiplatelet regimen. The benefit DM patients derive from early invasive therapy and use of GPIIb/IIIa receptor antagonists is well established, but these agents are underutilized in clinical practice. The addition of cilostazol to aspirin/clopidogrel dual antiplatelet therapy in patients with DM merits consideration though there remain concerns for its use in the ACS DM population. The results from the large clinical studies of prasugrel (TRITON-TIMI 38) and ticagrelor (PLATO) appear favorable for the use of these agents in conjunction with aspirin following PCI in DM patients. Although analysis of the diabetic patient subgroup in these landmark studies was prespecified, randomization was not performed. Consequently, outcome data from trials of these novel antiplatelet therapies, specifically recruiting high-risk DM patients, are eagerly awaited.

\section{Conflict of Interests}

The authors declare that there is no conflict of interests.

\section{References}

[1] Centers for Disease Control and Prevention, "National diabetes fact sheet: national estimates and general information on diabetes and prediabetes in the United States, 2011," in Department of Health and Human Services, G. A. Atlanta, Ed., Centers for Disease Control and Prevention, 2011.

[2] J. E. Shaw, R. A. Sicree, and P. Z. Zimmet, "Global estimates of the prevalence of diabetes for 2010 and 2030," Diabetes Research and Clinical Practice, vol. 87, no. 1, pp. 4-14, 2010.

[3] M. Laakso and S. Lehto, "Epidemiology of risk factors for cardiovascular disease in diabetes and impaired glucose tolerance," Atherosclerosis, vol. 137, pp. S65-S73, 1998.

[4] W. B. Kannel, R. B. D’Agostino, P. W. F. Wilson, A. J. Belanger, and D. R. Gagnon, "Diabetes, fibrinogen, and risk of cardiovascular disease: the Framingham experience," American Heart Journal, vol. 120, no. 3, pp. 672-676, 1990.

[5] M. Maiello, D. Boeri, F. Podesta et al., "Increased expression of tissue plasminogen activator and its inhibitor and reduced fibrinolytic potential of human endothelial cells cultured in elevated glucose," Diabetes, vol. 41, no. 8, pp. 1009-1015, 1992.

[6] L. Ang, V. Palakodeti, A. Khalid et al., "Elevated plasma fibrinogen and diabetes mellitus are associated with lower inhibition of platelet reactivity with clopidogrel," Journal of 
the American College of Cardiology, vol. 52, no. 13, pp. 10521059, 2008.

[7] M. Tominaga, H. Eguchi, H. Manaka, K. Igarashi, T. Kato, and A. Sekikawa, "Impaired glucose tolerance is a risk factor for cardiovascular disease, but not impaired fasting glucose: the Funagata diabetes study," Diabetes Care, vol. 22, no. 6, pp. 920-924, 1999.

[8] P. J. Lefèbvre, "Glucose metabolism and the postprandial state," European Journal of Clinical Investigation, vol. 29, supplement 2, pp. 1-6, 1999.

[9] M. Yngen, C. G. Östenson, N. Li, P. Hjemdahl, and N. H. Wallén, "Acute hyperglycemia increases soluble P-selectin in male patients with mild diabetes mellitus," Blood Coagulation and Fibrinolysis, vol. 12, no. 2, pp. 109-116, 2001.

[10] A. Undas, I. Wiek, E. Stêpień, K. Zmudka, and W. Tracz, "Hyperglycemia is associated with enhanced thrombin formation, platelet activation, and fibrin clot resistance to lysis in patients with acute coronary syndrome," Diabetes Care, vol. 31, no. 8, pp. 1590-1595, 2008.

[11] V. R. Vaidyula, A. K. Rao, M. Mozzoli, C. Homko, P. Cheung, and G. Boden, "Effects of hyperglycemia and hyperinsulinemia on circulating tissue factor procoagulant activity and platelet CD40 ligand," Diabetes, vol. 55, no. 1, pp. 202208, 2006.

[12] F. K. Keating, B. E. Sobel, and D. J. Schneider, "Effects of increased concentrations of glucose on platelet reactivity in healthy subjects and in patients with and without diabetes mellitus," American Journal of Cardiology, vol. 92, no. 11, pp. 1362-1365, 2003.

[13] R. Assert, G. Scherk, A. Bumbure, V. Pirags, H. Schatz, and A. F. H. Pfeiffer, "Regulation of protein kinase C by short term hyperglycaemia in human platelets in vivo and in vitro," Diabetologia, vol. 44, no. 2, pp. 188-195, 2001.

[14] M. Yncen, A. Norhammar, P. Hjemdahl, and N. H. Wallén, "Effects of improved metabolic control on platelet reactivity in patients with type 2 diabetes mellitus following coronary angioplasty," Diabetes and Vascular Disease Research, vol. 3, no. 1, pp. 52-56, 2006.

[15] J. B. Muhlestein, J. L. Anderson, B. D. Horne et al., "Effect of fasting glucose levels on mortality rate in patients with and without diabetes mellitus and coronary artery disease undergoing percutaneous coronary intervention," American Heart Journal, vol. 146, no. 2, pp. 351-358, 2003.

[16] R. A. Corpus, P. B. George, J. A. House et al., "Optimal glycemic control is associated with a lower rate of target vessel revascularization in treated type II diabetic patients undergoing elective percutaneous coronary intervention," Journal of the American College of Cardiology, vol. 43, no. 1, pp. 8-14, 2004.

[17] J. L. Wautier and A. M. Schmidt, "Protein glycation: a firm link to endothelial cell dysfunction," Circulation Research, vol. 95, no. 3, pp. 233-238, 2004.

[18] Y. Wang, W. Beck, R. Deppisch, S. M. Marshall, N. A. Hoenich, and M. G. Thompson, "Advanced glycation end products elicit externalization of phosphatidylserine in a subpopulation of platelets via $5-\mathrm{HT} 2 \mathrm{~A} / 2 \mathrm{C}$ receptors," American Journal of Physiology - Cell Physiology, vol. 293, no. 1, pp. C328-C336, 2007.

[19] P. D. Winocour, C. Watala, D. W. Perry, and R. L. KinloughRathbone, "Decreased platelet membrane fluidity due to glycation or acetylation of membrane proteins," Thrombosis and Haemostasis, vol. 68, no. 5, pp. 577-582, 1992.

[20] C. Watala, M. Boncer, J. Golański, W. Koziołkiewicz, Z. Trojanowski, and B. Walkowiak, "Platelet membrane lipid fluidity and intraplatelet calcium mobilization in type 2 diabetes mellitus," European Journal of Haematology, vol. 61, no. 5, pp. 319-326, 1998.

[21] D. Tschoepe, "The activated megakaryocyte-platelet-system in vascular disease: focus on diabetes," Seminars in Thrombosis and Hemostasis, vol. 21, no. 2, pp. 152-160, 1995.

[22] I. A. Ferreira, A. I. M. Mocking, M. A. H. Feijge et al., "Platelet inhibition by insulin is absent in type 2 diabetes mellitus," Arteriosclerosis, Thrombosis, and Vascular Biology, vol. 26, no. 2, pp. 417-422, 2006.

[23] B. Hechler, M. Cattaneo, and C. Gachet, "The P2 receptors in platelet function," Seminars in Thrombosis and Hemostasis, vol. 31, no. 2, pp. 150-161, 2005.

[24] N. Alexandru, D. Popov, A. Sbarcea, and M. Amuzescu, "Platelet free cytosolic calcium concentration during ageing of type 2 diabetic patients," Platelets, vol. 18, no. 7, pp. 473480, 2007.

[25] J. Pedreño, E. Hurt-Camejo, O. Wiklund, L. Badimón, and L. Masana, "Platelet function in patients with familial hypertriglyceridemia: evidence that platelet reactivity is modulated by apolipoprotein E content of very-low-density lipoprotein particles," Metabolism, vol. 49, no. 7, pp. 942-949, 2000.

[26] A. C. Calkin, B. G. Drew, A. Ono et al., "Reconstituted highdensity lipoprotein attenuates platelet function in individuals with type 2 diabetes mellitus by promoting cholesterol efflux," Circulation, vol. 120, no. 21, pp. 2095-2104, 2009.

[27] G. Ferretti, R. A. Rabini, T. Bacchetti et al., "Glycated low density lipoproteins modify platelet properties: a compositional and functional study," Journal of Clinical Endocrinology and Metabolism, vol. 87, no. 5, pp. 2180-2184, 2002.

[28] C. Falcon, G. Pfliegler, H. Deckmyn, and J. Vermylen, "The platelet insulin receptor: detection, partial characterizaztion, and search for a function," Biochemical and Biophysical Research Communications, vol. 157, no. 3, pp. 1190-1196, 1988.

[29] D. L. Hwang, C. F. Yen, and J. L. Nadler, "Insulin increases intracellular magnesium transport in human platelets," Journal of Clinical Endocrinology and Metabolism, vol. 76, no. 3, pp. 549-553, 1993.

[30] M. Trovati, G. Anfossi, P. Massucco et al., "Insulin stimulates nitric oxide synthesis in human platelets and, through nitric oxide, increases platelet concentrations of both guanosine-3', $5^{\prime}$-cyclic monophosphate and adenosine-3',5'cyclic monophosphate," Diabetes, vol. 46, no. 5, pp. 742-749, 1997.

[31] I. A. Ferreira, K. L. Eybrechts, A. I. M. Mocking, C. Kroner, and J. W. N. Akkerman, "IRS-1 Mediates Inhibition of Ca2+ Mobilization by Insulin via the Inhibitory G-protein Gi," Journal of Biological Chemistry, vol. 279, no. 5, pp. 32543264, 2004.

[32] R. W. Hunter and I. Hers, "Insulin/IGF-1 hybrid receptor expression on human platelets: consequences for the effect of insulin on platelet function," Journal of Thrombosis and Haemostasis, vol. 7, no. 12, pp. 2123-2130, 2009.

[33] I. Hers, "Insulin-like growth factor-1 potentiates platelet activation via the IRS/PI3K $\alpha$ pathway," Blood, vol. 110, no. 13, pp. 4243-4252, 2007.

[34] K. Hiramatsu, H. Nozaki, and S. Arimori, "Reduction of platelet aggregation induced by euglycaemic insulin clamp," Diabetologia, vol. 30, no. 5, pp. 310-313, 1987.

[35] M. Trovati, G. Anfossi, F. Cavalot, P. Massucco, E. Mularoni, and G. Emanuelli, "Insulin directly reduces platelet sensitivity to aggregating agents. Studies in vitro and in vivo," Diabetes, vol. 37, no. 6, pp. 780-786, 1988. 
[36] J. Westerbacka, H. Yki-Järvinen, A. Turpeinen et al., "Inhibition of platelet-collagen interaction: an in vivo action of insulin abolished by insulin resistance in obesity," Arteriosclerosis, Thrombosis, and Vascular Biology, vol. 22, no. 1, pp. 167-172, 2002.

[37] T. Murakami, H. Horigome, K. Tanaka et al., "Impact of weight reduction on production of platelet-derived microparticles and fibrinolytic parameters in obesity," Thrombosis Research, vol. 119, no. 1, pp. 45-53, 2007.

[38] B. B. Kahn and J. S. Flier, "Obesity and insulin resistance," Journal of Clinical Investigation, vol. 106, no. 4, pp. 473-481, 2000.

[39] S. Basili, G. Pacini, M. T. Guagnano et al., "Insulin resistance as a determinant of platelet activation in obese women," Journal of the American College of Cardiology, vol. 48, no. 12, pp. 2531-2538, 2006.

[40] G. Davì, M. T. Guagnano, G. Ciabattoni et al., "Platelet activation in obese women: role of inflammation and oxidant stress," Journal of the American Medical Association, vol. 288, no. 16, pp. 2008-2014, 2002.

[41] M. Ishida, T. Ishida, N. Ono et al., "Effects of insulin on calcium metabolism and platelet aggregation," Hypertension, vol. 28, no. 2, pp. 209-212, 1996.

[42] D. J. Angiolillo, E. Bernardo, C. Ramírez et al., "Insulin therapy is associated with platelet dysfunction in patients with type 2 diabetes mellitus on dual oral antiplatelet treatment," Journal of the American College of Cardiology, vol. 48, no. 2, pp. 298-304, 2006.

[43] D. J. Betteridge, K. E. H. El Tahir, J. P. D. Reckless, and K. Williams, "Platelets from diabetic subjects show diminished sensitivity to prostacyclin," European Journal of Clinical Investigation, vol. 12, no. 5, pp. 395-398, 1982.

[44] G. Anfossi, E. M. Mularoni, S. Burzacca et al., "Platelet resistance to nitrates in obesity and obese NIDDM, and normal platelet sensitivity to both insulin and nitrates in lean NIDDM," Diabetes Care, vol. 21, no. 1, pp. 121-126, 1998.

[45] V. R. Vaidyula, G. Boden, and A. K. Rao, "Platelet and monocyte activation by hyperglycemia and hyperinsulinemia in healthy subjects," Platelets, vol. 17, no. 8, pp. 577-585, 2006.

[46] P. C. Redondo, I. Jardin, J. M. Hernández-Cruz, J. A. Pariente, G. M. Salido, and J. A. Rosado, "Hydrogen peroxide and peroxynitrite enhance $\mathrm{Ca} 2+$ mobilization and aggregation in platelets from type 2 diabetic patients," Biochemical and Biophysical Research Communications, vol. 333, no. 3, pp. 794-802, 2005.

[47] J. E. Freedman, "Oxidative stress and platelets," Arteriosclerosis, Thrombosis, and Vascular Biology, vol. 28, no. 3, pp. s11s16, 2008.

[48] I. Jardín, P. C. Redondo, G. M. Salido, J. A. Pariente, and J. A. Rosado, "Endogenously generated reactive oxygen species reduce PMCA activity in platelets from patients with noninsulin-dependent diabetes mellitus," Platelets, vol. 17, no. 5, pp. 283-288, 2006.

[49] L. Monnier, E. Mas, C. Ginet et al., "Activation of oxidative stress by acute glucose fluctuations compared with sustained chronic hyperglycemia in patients with type 2 diabetes," Journal of the American Medical Association, vol. 295, no. 14, pp. 1681-1687, 2006.

[50] G. Davì, G. Ciabattoni, A. Consoli et al., "In vivo formation of 8-iso-prostaglandin and platelet activation in diabetes mellitus: effects of improved metabolic control and vitamin E supplementation," Circulation, vol. 99, no. 2, pp. 224-229, 1999.
[51] M. J. Sampson, N. Gopaul, I. R. Davies, D. A. Hughes, and M. J. Carrier, "Plasma F2 isoprostanes: direct evidence of increased free radical damage during acute hyperglycemia in type 2 diabetes," Diabetes Care, vol. 25, no. 3, pp. 537-541, 2002.

[52] G. Schaeffer, T. C. Wascher, G. M. Kostner, and W. F. Graier, "Alterations in platelet CA2 + signalling in diabetic patients is due to increased formation of superoxide anions and reduced nitric oxide production," Diabetologia, vol. 42, no. 2, pp. 167176, 1999.

[53] A. M. Schmidt, S. D. Yan, J. L. Wautier, and D. Stern, "Activation of receptor for advanced glycation end products: a mechanism for chronic vascular dysfunction in diabetic vasculopathy and atherosclerosis," Circulation Research, vol. 84, no. 5, pp. 489-497, 1999.

[54] G. Spinetti, N. Kraenkel, C. Emanueli, and P. Madeddu, "Diabetes and vessel wall remodelling: from mechanistic insights to regenerative therapies," Cardiovascular Research, vol. 78, no. 2, pp. 265-273, 2008.

[55] D. J. Schneider, "Factors contributing to increased platelet reactivity in people with diabetes," Diabetes Care, vol. 32, no. 4, pp. 525-527, 2009.

[56] K. Belostocki, L. Pricop, P. B. Redecha et al., "Infliximab treatment shifts the balance between stimulatory and inhibitory Fc $\gamma$ receptor type II isoforms on neutrophils in patients with rheumatoid arthritis," Arthritis and Rheumatism, vol. 58, no. 2, pp. 384-388, 2008.

[57] D. Tschoepe, P. Roesen, J. Esser et al., "Large platelets circulate in an activated state in diabetes mellitus," Seminars in Thrombosis and Hemostasis, vol. 17, no. 4, pp. 433-438, 1991.

[58] S. Guthikonda, E. I. Lev, R. Patel et al., "Reticulated platelets and uninhibited COX-1 and COX-2 decrease the antiplatelet effects of aspirin," Journal of Thrombosis and Haemostasis, vol. 5, no. 3, pp. 490-496, 2007.

[59] S. Guthikonda, C. L. Alviar, M. Vaduganathan et al., "Role of reticulated platelets and platelet size heterogeneity on platelet activity after dual antiplatelet therapy with aspirin and clopidogrel in patients with stable coronary artery disease," Journal of the American College of Cardiology, vol. 52, no. 9, pp. 743-749, 2008.

[60] Antithrombotic Trialists' Collaboration, "Collaborative meta-analysis of randomised trials of antiplatelet therapy for prevention of death, myocardial infarction, and stroke in high risk patients," British Medical Journal, vol. 324, no. 7329, pp. 71-86, 2002.

[61] R. Beigel, H. Hod, P. Fefer et al., "Relation of aspirin failure to clinical outcome and to platelet response to aspirin in patients with acute myocardial infarction," American Journal of Cardiology, vol. 107, no. 3, pp. 339-342, 2011.

[62] G. Krasopoulos, S. J. Brister, W. S. Beattie, and M. R. Buchanan, "Aspirin "resistance" and risk of cardiovascular morbidity: systematic review and meta-analysis," BMJ, vol. 336, no. 7637, pp. 195-198, 2008.

[63] J. W. Eikelboom, J. Hirsh, J. I. Weitz, M. Johnston, Q. Yi, and S. Yusuf, "Aspirin-resistant thromboxane biosynthesis and the risk of myocardial infarction, stroke, or cardiovascular death in patients at high risk for cardiovascular events," Circulation, vol. 105, no. 14, pp. 1650-1655, 2002.

[64] N. J. Breet, J. W. Van Werkum, H. J. Bouman, J. C. Kelder, J. M. Ten Berg, and C. M. Hackeng, "High onaspirin platelet reactivity as measured with aggregationbased, cyclooxygenase- 1 inhibition sensitive platelet function tests is associated with the occurrence of atherothrombotic 
events," Journal of Thrombosis and Haemostasis, vol. 8, no. 10, pp. 2140-2148, 2010.

[65] J. L. Reny, P. De Moerloose, M. Dauzat, and P. Fontana, "Use of the PFA-100 closure time to predict cardiovascular events in aspirin-treated cardiovascular patients: a systematic review and meta-analysis," Journal of Thrombosis and Haemostasis, vol. 6, no. 3, pp. 444-450, 2008.

[66] S. Fateh-Moghadam, U. Plöckinger, N. Cabeza et al., "Prevalence of aspirin resistance in patients with type 2 diabetes," Acta Diabetologica, vol. 42, no. 2, pp. 99-103, 2005.

[67] S. S. Mehta, R. J. Silver, A. Aaronson, M. Abrahamson, and A. B. Goldfine, "Comparison of Aspirin resistance in type 1 versus type 2 diabetes mellitus," American Journal of Cardiology, vol. 97, no. 4, pp. 567-570, 2006.

[68] D. M. Becker, J. Segal, D. Vaidya et al., "Sex differences in platelet reactivity and response to low-dose aspirin therapy," Journal of the American Medical Association, vol. 295, no. 12, pp. 1420-1427, 2006.

[69] T. J. Gluckman, R. C. McLean, S. P. Schulman et al., "Effects of aspirin responsiveness and platelet reactivity on early vein graft thrombosis after coronary artery bypass graft surgery," Journal of the American College of Cardiology, vol. 57, no. 9, pp. 1069-1077, 2011.

[70] A. W. Chung, P. Jurasz, M. D. Hollenberg, and M. W. Radomski, "Mechanisms of action of proteinase-activated receptor agonists on human platelets," British Journal of Pharmacology, vol. 135, no. 5, pp. 1123-1132, 2002.

[71] S. Yusuf, F. Zhao, S. R. Mehta, S. Chrolavicius, G. Tognoni, and K. K. Fox, "Effects of clopidogrel in addition to aspirin in patients with acute coronary syndromes without ST-segment elevation," New England Journal of Medicine, vol. 345, no. 7, pp. 494-502, 2001.

[72] D. L. Bhatt, K. A. A. Fox, W. Hacke et al., "Clopidogrel and aspirin versus aspirin alone for the prevention of atherothrombotic events," New England Journal of Medicine, vol. 354, no. 16, pp. 1706-1717, 2006.

[73] T. Geisler, H. Langer, M. Wydymus et al., "Low response to clopidogrel is associated with cardiovascular outcome after coronary stent implantation," European Heart Journal, vol. 27, no. 20, pp. 2420-2425, 2006.

[74] P. A. Gurbel, K. P. Bliden, W. Samara et al., "Clopidogrel effect on platelet reactivity in patients with stent thrombosis: results of the CREST study," Journal of the American College of Cardiology, vol. 46, no. 10, pp. 1827-1832, 2005.

[75] W. Hochholzer, D. Trenk, H. P. Bestehorn et al., "Impact of the degree of peri-interventional platelet inhibition after loading with clopidogrel on early clinical outcome of elective coronaryc stent placement," Journal of the American College of Cardiology, vol. 48, no. 9, pp. 1742-1750, 2006.

[76] S. Matetzky, B. Shenkman, V. Guetta et al., "Clopidogrel resistance is associated with increased risk of recurrent atherothrombotic events in patients with acute myocardial infarction," Circulation, vol. 109, no. 25, pp. 3171-3175, 2004.

[77] N. J. Breet, J. W. Van Werkum, H. J. Bouman et al., "Comparison of platelet function tests in predicting clinical outcome in patients undergoing coronary stent implantation," Journal of the American Medical Association, vol. 303, no. 8, pp. 754$762,2010$.

[78] K. W. Park et al., "Clinical predictors of high posttreatment platelet reactivity to clopidogrel in Koreans," Cardiovascular Therapeutics. In press.

[79] D. J. Angiolillo, A. Fernandez-Ortiz, E. Bernardo et al., "Platelet function profiles in patients with type 2 diabetes and coronary artery disease on combined aspirin and clopidogrel treatment," Diabetes, vol. 54, no. 8, pp. 2430-2435, 2005.

[80] D. J. Angiolillo, S. B. Shoemaker, B. Desai et al., "Randomized comparison of a high clopidogrel maintenance dose in patients with diabetes mellitus and coronary artery disease: results of the optimizing antiplatelet therapy in diabetes mellitus (OPTIMUS) study," Circulation, vol. 115, no. 6, pp. 708-716, 2007.

[81] F. Mangiacapra, G. Patti, A. Peace et al., "Comparison of platelet reactivity and periprocedural outcomes in patients with versus without diabetes mellitus and treated with clopidogrel and percutaneous coronary intervention," American Journal of Cardiology, vol. 106, no. 5, pp. 619-623, 2010.

[82] F. Mangiacapra, A. J. Peace, W. Wijns, and E. Barbato, "Lack of correlation between platelet reactivity and glycaemic control in type 2 diabetes mellitus patients treated with aspirin and clopidogrel," Journal of Thrombosis and Thrombolysis, pp. $1-5,2011$.

[83] A. M. Harmsze, J. W. Van Werkum, F. Moral et al., "Sulfonylureas and on-clopidogrel platelet reactivity in type 2 diabetes mellitus patients," Platelets, vol. 22, no. 2, pp. 98 $102,2011$.

[84] S. Goto, "Cilostazol: potential mechanism of action for antithrombotic effects accompanied by a low rate of bleeding," Atherosclerosis Supplements, vol. 6, no. 4, pp. 3-11, 2005.

[85] Y. H. Jeong, S. W. Lee, B. R. Choi et al., "Randomized comparison of adjunctive cilostazol versus high maintenance dose clopidogrel in patients with high post-treatment platelet reactivity. results of the ACCEL-RESISTANCE (Adjunctive Cilostazol Versus High Maintenance Dose Clopidogrel in Patients With Clopidogrel Resistance) randomized study," Journal of the American College of Cardiology, vol. 53, no. 13, pp. 1101-1109, 2009.

[86] D. J. Angiolillo, P. Capranzano, S. Goto et al., "A randomized study assessing the impact of cilostazol on platelet function profiles in patients with diabetes mellitus and coronary artery disease on dual antiplatelet therapy: results of the OPTIMUS2 study," European Heart Journal, vol. 29, no. 18, pp. 22022211, 2008.

[87] S. W. Lee, S. W. Park, S. C. Yun et al., "Triple antiplatelet therapy reduces ischemic events after drug-eluting stent implantation: Drug-Eluting stenting followed by Cilostazol treatment REduces Adverse Serious cardiac Events (DECREASE registry)," American Heart Journal, vol. 159, no. 2, pp. 284.e1-291.e1, 2010.

[88] J. W. Suh et al., "Multicenter randomized trial evaluating the efficacy of cilostazol on ischemic vascular complications after drug-eluting stent implantation for coronary heart disease: results of the CILON-T (influence of CILostazol-based triple antiplatelet therapy $\mathrm{ON}$ ischemic complication after drugeluting stenT implantation) trial," Journal of the American College of Cardiology, vol. 57, pp. 280-289, 2011.

[89] K. W. Park, J. J. Park, S. -P. Lee et al., "Cilostazol attenuates on-treatment platelet reactivity in patients with CYP2C19 loss of function alleles receiving dual antiplatelet therapy: a genetic substudy of the CILON-T randomised controlled trial," Heart, vol. 97, no. 8, pp. 641-647, 2011.

[90] M. Roffi, "Early invasive strategy in the diabetic patient with non-ST-segment elevation acute coronary syndromes," European Heart Journal, Supplements, vol. 7, pp. K19-K22, 2005.

[91] E. D. Peterson, C. V. Pollack, M. T. Roe et al., "Early use of glycoprotein IIb/IIIa inhibitors in non-ST-elevation acute myocardial infarction: observations from the national 
registry of myocardial infarction 4," Journal of the American College of Cardiology, vol. 42, no. 1, pp. 45-53, 2003.

[92] P. W. Radke and H. Schunkert, "Diabetics with acute coronary syndrome: advances, challenges, and uncertainties," European Heart Journal, vol. 31, no. 24, pp. 2971-2973, 2010.

[93] J. A. Jakubowski, K. J. Winters, H. Naganuma, and L. Wallentin, "Prasugrel: a novel thienopyridine antiplatelet agent. A review of preclinical and clinical studies and the mechanistic basis for its distinct antiplatelet profile," Cardiovascular Drug Reviews, vol. 25, no. 4, pp. 357-374, 2007.

[94] S. D. Wiviott, D. Trenk, A. L. Frelinger et al., "Prasugrel compared with high loading- and maintenance-dose clopidogrel in patients with planned percutaneous coronary intervention: the prasugrel in comparison to clopidogrel for inhibition of platelet activation and aggregation-thrombolysis in myocardial infarction 44 trial," Circulation, vol. 116, no. 25, pp. 2923-2932, 2007.

[95] S. D. Wiviott, E. Braunwald, D. J. Angiolillo et al., "Greater clinical benefit of more intensive oral antiplatelet therapy with prasugrel in patients with diabetes mellitus in the trial to assess improvement in therapeutic outcomes by optimizing platelet inhibition with prasugrel-thrombolysis in myocardial infarction 38," Circulation, vol. 118, no. 16, pp. 1626-1636, 2008.

[96] F. G. Kushner, "2009 focused updates: ACC/AHA guidelines for the management of patients with ST-elevation myocardial infarction (Updating the 2004 Guideline and 2007 Focused Update) and ACC/AHA/SCAI guidelines on percutaneous coronary intervention (Updating the 2005 Guideline and 2007 Focused Update): a report of the American College of Cardiology Foundation/American Heart Association Task Force on Practice Guidelines," Circulation, vol. 120, pp. $2271-$ 2306, 2009.

[97] J. S. Berger, M. T. Roe, C. M. Gibson et al., "Safety and feasibility of adjunctive antiplatelet therapy with intravenous elinogrel, a direct-acting and reversible P2Y12 ADP-receptor antagonist, before primary percutaneous intervention in patients with ST-elevation myocardial infarction: the Early Rapid ReversAl of Platelet ThromboSis with Intravenous Elinogrel before PCI to Optimize REperfusion in Acute Myocardial Infarction (ERASE MI)," American Heart Journal, vol. 158, no. 6, pp. 998.e1-1004.e1, 2009.

[98] S. V. Rao et al., "A randomized, double-blind, active controlled trial to evaluate intravenous and oral PRT060128 (elinogrel), a selective and reversible $\mathrm{P} 2 \mathrm{Y} 12$ receptor inhibitor vs clopidogrel as a novel antiplatelet therapy in patients undergoing nonurgent percutaneous coronary interventions," in Proceedings of the European Society of Cardiology Congress, Stockholm, Sweden, 2010.

[99] J. L. Mega, S. L. Close, S. D. Wiviott et al., "Genetic variants in ABCB1 and CYP2C19 and cardiovascular outcomes after treatment with clopidogrel and prasugrel in the TRITONTIMI 38 trial: a pharmacogenetic analysis," The Lancet, vol. 376, no. 9749, pp. 1312-1319, 2010.

[100] P. A. Gurbel, K. P. Bliden, K. Butler et al., "Response to ticagrelor in clopidogrel nonresponders and responders and effect of switching therapies: the RESPOND study," Circulation, vol. 121, no. 10, pp. 1188-1199, 2010.

[101] P. A. Gurbel, K. P. Bliden, K. Butler et al., "Randomized double-blind assessment of the ONSET and OFFSET of the antiplatelet effects of ticagrelor versus clopidogrel in patients with stable coronary artery disease: the ONSET/OFFSET study," Circulation, vol. 120, no. 25, pp. 2577-2585, 2009.
[102] L. Wallentin, R. C. Becker, A. Budaj et al., "Ticagrelor versus clopidogrel in patients with acute coronary syndromes," New England Journal of Medicine, vol. 361, no. 11, pp. 1045-1057, 2009.

[103] S. James, D. J. Angiolillo, J. H. Cornel et al., "Ticagrelor vs. clopidogrel in patients with acute coronary syndromes and diabetes: a substudy from the PLATelet inhibition and patient Outcomes (PLATO) trial," European Heart Journal, vol. 31, no. 24, pp. 3006-3016, 2010.

[104] M. Lotrionte, G. G. L. Biondi-Zoccai, P. Agostoni et al., "Meta-analysis appraising high clopidogrel loading in patients undergoing percutaneous coronary intervention," American Journal of Cardiology, vol. 100, no. 8, pp. 11991206, 2007.

[105] M. J. Price, P. B. Berger, P. S. Teirstein et al., "Standardvs high-dose clopidogrel based on platelet function testing after percutaneous coronary intervention: the GRAVITAS randomized trial," Journal of the American Medical Association, vol. 305, no. 11, pp. 1097-1105, 2011.

[106] M. Chintala, K. Shimizu, M. Ogawa, H. Yamaguchi, M. Doi, and P. Jensen, "Basic and translational research on proteinase-activated receptors: antagonism of the proteinaseactivated receptor 1 for thrombin, a novel approach to antiplatelet therapy for atherothrombotic disease," Journal of Pharmacological Sciences, vol. 108, no. 4, pp. 433-438, 2008.

[107] D. A. Morrow, B. M. Scirica, K. A. A. Fox et al., "Evaluation of a novel antiplatelet agent for secondary prevention in patients with a history of atherosclerotic disease: design and rationale for the Thrombin-Receptor Antagonist in Secondary Prevention of Atherothrombotic Ischemic Events (TRA ${ }^{\circ} P$ )-TIMI 50 trial," American Heart Journal, vol. 158, no. 3, pp. 335.e3-341.e3, 2009.

[108] The TRA-CER Executive and Steering Committees, "The thrombin receptor antagonist for clinical event reduction in acute coronary syndrome (TRA $* \mathrm{CER})$ trial: study design and rationale," American Heart Journal, vol. 158, pp. 327.e4334.e4, 2009.

[109] S. Goto, H. Ogawa, M. Takeuchi, M. D. Flather, and D. L. Bhatt, "Double-blind, placebo-controlled Phase II studies of the protease-activated receptor 1 antagonist E5555 (atopaxar) in Japanese patients with acute coronary syndrome or high-risk coronary artery disease," European Heart Journal, vol. 31, no. 21, pp. 2601-2613, 2010.

[110] M. G. Hennerici, M. L. Bots, I. Ford, S. Laurent, and P. J. Touboul, "Rationale, design and population baseline characteristics of the PERFORM vascular project: an ancillary study of the Prevention of cerebrovascular and cardiovascular events of ischemic origin with terutroban in patients with a history of ischemic stroke or transient ischemic attack (PERFORM) trial," Cardiovascular Drugs and Therapy, vol. 24, no. 2, pp. 175-180, 2010.

[111] J. Chen, D. L. Bhatt, E. S. Dunn et al., "Cost-effectiveness of clopidogrel plus aspirin versus aspirin alone for secondary prevention of cardiovascular events: results from the CHARISMA trial," Value in Health, vol. 12, no. 6, pp. 872879, 2009.

[112] A. Dasgupta, S. R. Steinhubl, D. L. Bhatt et al., "Clinical outcomes of patients with diabetic nephropathy randomized to clopidogrel plus aspirin versus aspirin alone (a post hoc analysis of the clopidogrel for high atherothrombotic risk and ischemic stabilization, management, and avoidance [CHARISMA] trial)," American Journal of Cardiology, vol. 103, no. 10, pp. 1359-1363, 2009. 
[113] M. Pignone and C. D. Williams, "Aspirin for primary prevention of cardiovascular disease in diabetes mellitus," Nature Reviews Endocrinology, vol. 6, no. 11, pp. 619-628, 2010.

[114] M. Pignone, M. J. Alberts, J. A. Colwell et al., "Aspirin for primary prevention of cardiovascular events in people with diabetes: a position statement of the american diabetes association, a scientific statement of the american heart association, and an expert consensus document of the american college of cardiology foundation," Circulation, vol. 121, no. 24, pp. 2694-2701, 2010. 


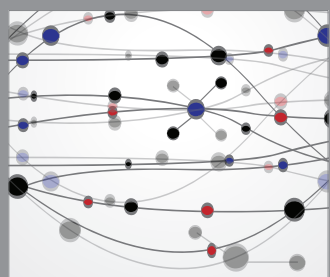

The Scientific World Journal
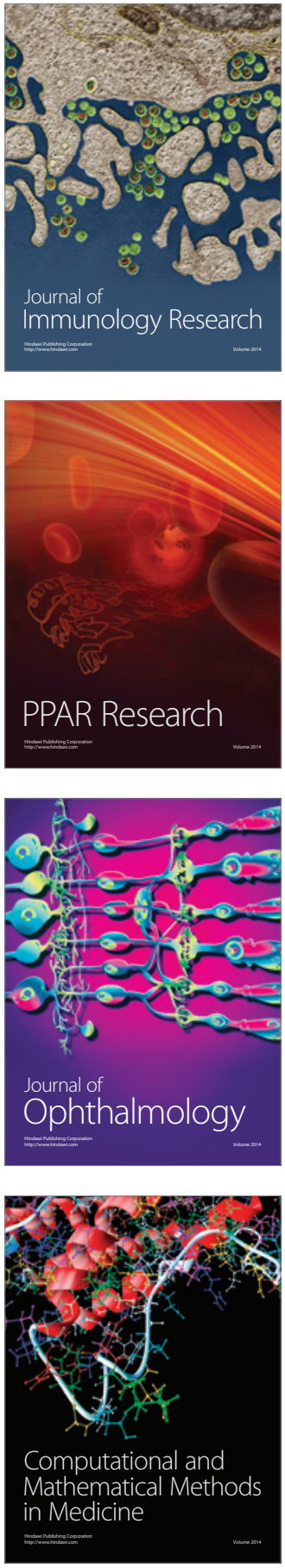

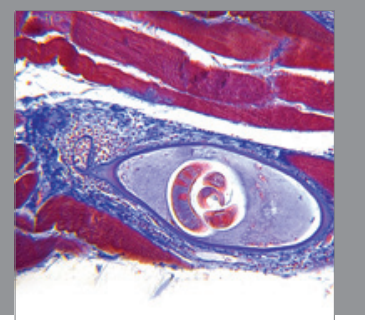

Gastroenterology

Research and Practice
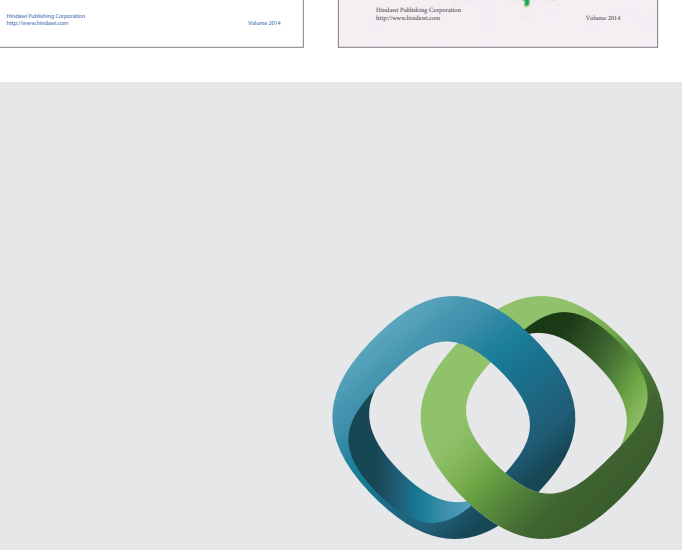

\section{Hindawi}

Submit your manuscripts at

http://www.hindawi.com
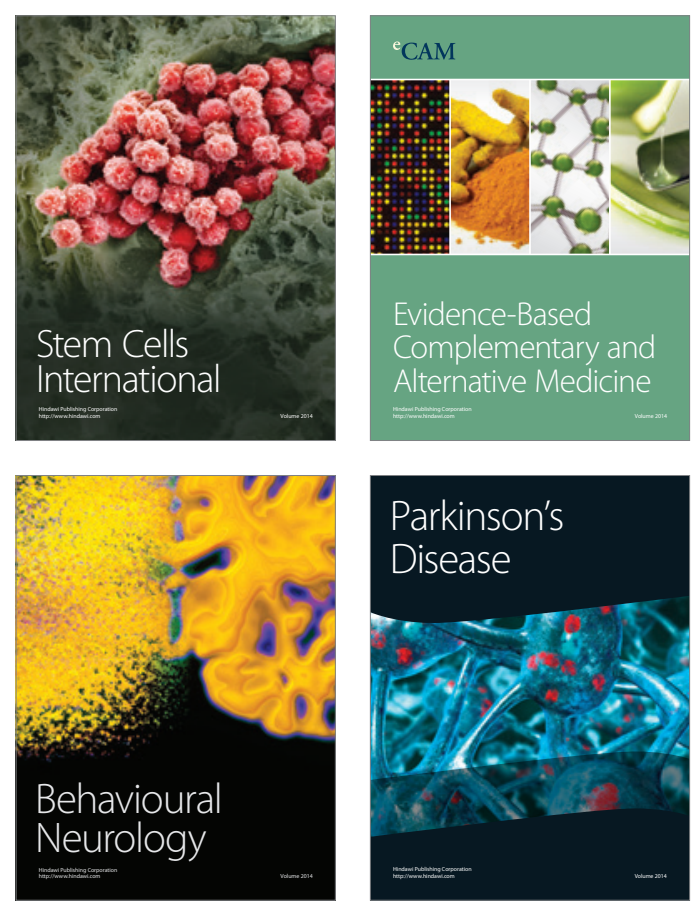

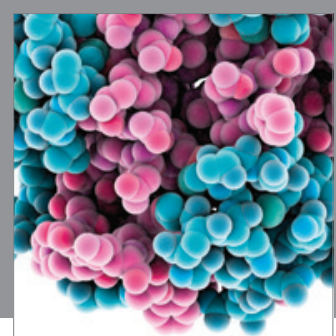

Journal of
Diabetes Research

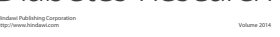

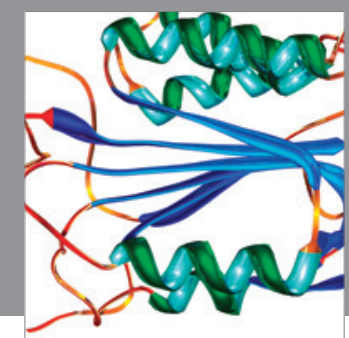

Disease Markers
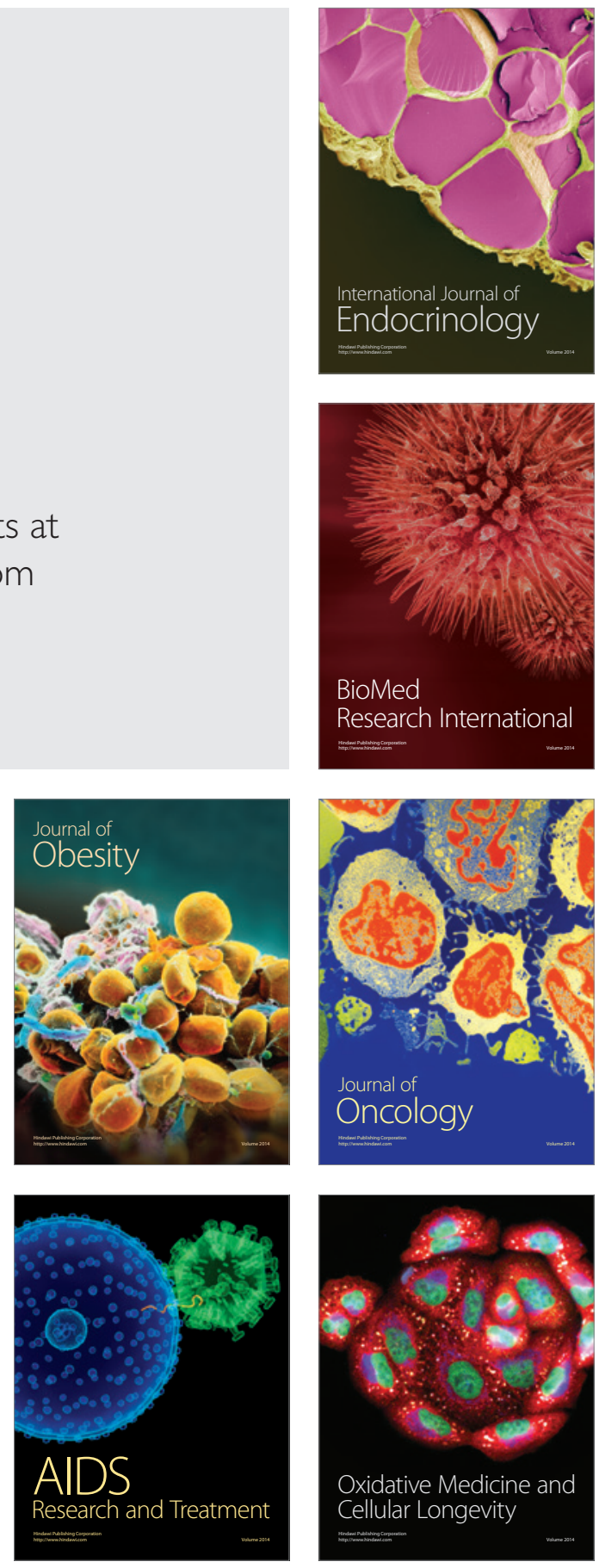